\title{
A CURRICULARIZAÇÃO DA EXTENSÃO E SUA APLICAÇÃO NAS ESCOLAS DE ENGENHARIA
}

Rodrigo Cutri-rodrigo.cutri@maua.br

Instituto Mauá de Tecnologia

Praça Mauá, 1

09580-900 - São Caetano do Sul - SP

Hector Alexandre Chaves Gil - hector.gil@maua.br

Instituto Mauá de Tecnologia

Praça Mauá, 1

09580-900 - São Caetano do Sul - SP

Patrícia Antônio de Menezes Freitas - pantonio@maua.br

Instituto Mauá de Tecnologia

Praça Mauá, 1

09580-900 - São Caetano do Sul - SP

Resumo: A curricularização da extensão, ou creditação (curricular) da extensão, estratégia prevista no Plano Nacional de Educação (PNE), foi regulamentada pela Resolução $n^{\circ} 7$ $M E C / C N E / C E S$, de 18 de dezembro de 2018. Esta resolução traz como grande questão a ser implantada nas Instituições de Ensino Superior, o cumprimento dos $10 \%$ de carga horária mínima dedicada à extensão. Mas a grande questão permanece: como desenvolver um currículo que contemple esse percentual de carga horária sem comprometer os conteúdos que devem ser desenvolvidos no curso? Qual o perfil do docente? Como as Escolas de Engenharia estão se adaptando? Este artigo apresenta um levantamento feito junto as Escolas de Engenharia associadas à ABENGE e a seguir apresenta uma visão geral sobre as propostas em andamento.

Palavras-chave: DCN, Curricularização. Extensão.

\section{INTRODUÇÃO}

A Resolução $n^{\circ} 7$ MEC/CNE/CES, de 18 de dezembro de 2018 que Estabelece as Diretrizes para a Extensão na Educação Superior (MEC, 2018):

- estabelece que as atividades de extensão devem compor, no mínimo, $10 \%$ (dez por cento) do total da carga horária curricular estudantil dos cursos de graduação, as quais deverão fazer parte da matriz curricular dos cursos;

- instrui o INEP a considerar, para efeitos de autorização e reconhecimento de cursos, o cumprimento dos $10 \%$ de carga horária mínima dedicada à extensão, a articulação entre atividades de extensão, ensino e pesquisa, e dentre outras coisas;

- define que haja docentes responsáveis pela orientação das atividades de extensão nos cursos de graduação. 
Pela resolução, as atividades de extensão devem ter sua proposta, desenvolvimento e conclusão, devidamente registrados, documentados e analisados, de forma que seja possível organizar os planos de trabalho, as metodologias, os instrumentos e os conhecimentos gerados. As atividades de extensão devem ser sistematizadas e acompanhadas, com o adequado assentamento, além de registradas, fomentadas e avaliadas por instâncias administrativas institucionais, devidamente estabelecidas, em regimento próprio. Toda esta demanda de sistematização gerou o que se denominou "Curricularização da Extensão".

O próprio MEC traz desta vez uma visão diferente do que se considerava extensão pois preconiza que haja um papel ativo do estudante junto as atividades que serão desenvolvidas e não apenas a simples participação do estudante em alguma atividade externa. São consideradas atividades de extensão as intervenções que envolvam diretamente as comunidades externas às instituições de ensino superior e que estejam vinculadas à formação do estudante.

Os $10 \%$ de atividades de extensão devem ser calculados com base na carga horária total do curso, que é a soma dos componentes curriculares, incluindo disciplinas, atividades complementares, estágios, trabalho de conclusão do curso etc. Exemplo: em um curso com carga horária total de 3.600 horas, cada aluno deverá cumprir 360 h em atividades de extensão para graduar-se, conforme critérios estabelecidos no Projeto Pedagógico do Curso.

\section{QUESTÕES QUANTO A IMPLANTAÇÃO DA CURRICULARIZAÇÃO DA EXTENSÃO}

Ao buscar o desenvolvimento de um currículo que contemple a curricularização da extensão, há inicialmente a possibilidade de ampliação ou não da carga horária do curso.

Na percepção dos autores, não é recomendável que a carga horária seja aumentada pois implicaria em mais tempo para formação do profissional. Tal percepção é compartilhada pela totalidade das instituições pesquisadas (ver item 3). Nelas a curricularização da extensão se deu ou está sendo planejada para ser integrada à matriz e total de carga horária existente. A questão é então, como ministrar determinados conteúdos programáticos ou a realização de determinados objetivos de aprendizagem por meio da realização de ações de extensão, em lugar das metodologias tradicionais (aulas teóricas ou práticas laboratoriais).

Assim, o Colegiado de Curso, assessorado pelo Núcleo Docente Estruturante, deverá realizar um diagnóstico para avaliar:

(a) quais disciplinas já realizam atividades extensão ou têm potencial de realizá-la;

(b) qual a carga horária dessas disciplinas deverá ser dedicada às atividades de extensão.

Para fins de curricularização, cada curso deverá estabelecer em seu Projeto Pedagógico a maneira como os alunos deverão realizar as atividades de extensão, dentre as seguintes possibilidades:

- ações de extensão incorporadas às unidades curriculares, ou seja, incorporadas a disciplinas, que passarão a dedicar parte ou toda a carga horária a tais atividades; 
- ações de extensão registradas em sistema próprio (projetos, cursos ou eventos), que deverão ser certificadas e validadas, conforme critérios estabelecidos no PPC, para creditação das horas ao aluno;

- composição dos itens anteriores, ou seja, o PPC pode estabelecer que algumas horas deverão ser cumpridas em tais e quais disciplinas e o restante em ações registradas em sistema próprio.

Ainda segundo a Resolução MEC, as atividades de Extensão, segundo sua caracterização nos projetos políticos pedagógicos dos cursos, se inserem nas seguintes modalidades:

I - programas

II - projetos

III - cursos e oficinas

IV - eventos

$\mathrm{V}$ - prestação de serviços

As modalidades incluem, além dos programas institucionais, eventualmente também as de natureza governamental, que atendam às políticas municipais, estaduais, distrital e nacional.

De acordo com a Lei n. 11.788 , de 25 de setembro de 2008, estágio é ato educativo escolar supervisionado, desenvolvido em ambiente de trabalho, que visa à preparação para o trabalho produtivo, assim, as horas de estágio realizadas pelos estudantes não podem ser creditadas para curricularização da extensão. O mesmo ocorre com a iniciação científica, visto que as atividades de pesquisa são contabilizadas no currículo como atividades complementares. Um cuidado especial deve ser tomado com as aulas de campo, visitas técnicas, científicas ou culturais (atividades complementares) que podem ser creditadas como atividades de extensão se estabelecerem uma interação dialógica da comunidade acadêmica com a sociedade por meio da troca de conhecimentos.

\section{A CURRICULIZAÇÃO NAS ESCOLAS DE ENGENHARIA}

Inicialmente realizou-se uma pesquisa sobre referências sobre a curricularização da extensão já existentes em escolas de Engenharia na Internet: (UFSC, 2019), (IFSC, 2019), (UNB, 2019), (UPE, 2019), (UERN, 2019), (UFAL, 2019), (UFC, 2019), (UFMG, 2019), (UFRJ, 2019), (UNIFESP, 2019), (UFPEL, 2019), (Benetti, P. C.; Sousa, A. I.; Souza, M. H. N., 2019), (Imperatore, S. L. B.; Pedde, V, 2019), (Collado, D. M.; Oliveira, N. C.; Carneiro, P. O, 2019), (Coimbra, A. L. S; Sousa, A. I.; Figueiredo, I. V.; Leite, S. , 2019), (ABMES, 2019) e (Serva, F. M., Brandão, C. da Fonseca., 2019).

Verificou-se que grande parte do material encontrado tratava de iniciativas realizadas em Instituições Públicas, notadamente federais ou orientações mais gerais fornecidas por associações de mantenedoras do Ensino Superior. A fim de apurar, de modo mais geralizado, para instituições públicas e privadas, quais os preparativos e como as Escolas de Engenharia estão se preparando para se adaptar as necessidades demandadas pela Curricularização da Extensão, foi submetido por meio da ABENGE -Associação Brasileira de Educação em Engenharia questionário online, usando-se a ferramenta Google Forms, à todos os seus associados. Foram compiladas 53 respostas sendo $41(77,4 \%)$ de IES Públicas e $12(22,6 \%)$ de IES Privadas. 
A seguir são apresentadas e discutidas as respostas recebidas:

Questão 1: Você já conhece a RESOLUÇÃO N 7, DE 18 DE DEZEMBRO DE 2018 que estabelece as Diretrizes para as Políticas de Extensão da Educação Superior Brasileira?

\begin{tabular}{|l|l|}
\hline IES Pública & Sim $-36(88 \%)$ / Não $-5(12 \%)$ \\
\hline IES Privada & Sim $-9(75 \%) /$ Não $-3(25 \%)$ \\
\hline
\end{tabular}

Observa-se que a discussão está mais avançada na rede pública, fato corroborado por (Coimbra, A. L. S; Sousa, A. I.; Figueiredo, I. V.; Leite, S. , 2019). O que mostra que ainda há muito a avançar no conhecimento da prática desta nova resolução nas IES privadas.

Questão 2: Sua instituição vem promovendo o debate sobre a extensão junto ao corpo docente?

\begin{tabular}{|l|l|}
\hline IES Pública & Sim $-27(66 \%)$ / Não $-14(34 \%)$ \\
\hline IES Privada & Sim $-8(67 \%) /$ Não $-4(33 \%)$ \\
\hline
\end{tabular}

Observa-se que apesar da discussão estar avançando nas IES que já conhecem a resolução. O debate junto ao corpo docente carece ainda de melhor aprofundamento pois quase $1 / 3$ dos respondentes não verifica o debate sobre a questão em sua IES.

Questão 3: Se a resposta anterior foi sim, como este debate vêm sendo realizado?

\begin{tabular}{|l|l|}
\hline IES Pública & $\begin{array}{l}56 \% \text { Discussão junto aos NDEs } \\
19 \% \text { Seminários e debates junto à comunidade acadêmica }\end{array}$ \\
& $\begin{array}{l}15 \% \text { Seminários e debates junto aos coordenadores de curso } \\
11 \% \text { Workshops voltados à extensão }\end{array}$ \\
\hline IES Privada & $\begin{array}{l}\text { 63\% Discussão junto aos NDEs } \\
13 \% \text { Seminários e debates junto aos coordenadores de curso } \\
\end{array}$ \\
& $25 \%$ Workshops voltados à extensão \\
\hline
\end{tabular}

Nota-se que tanto nas IES Públicas como as Privadas o debate vem sendo efetuado com o NDE dos cursos, mas a disseminação prática da execução por meio de oficinas ou workshops ainda não está sendo plenamente realizado. Tal fato abre caminho para a oferta de workshops deste tipo pela própria ABENGE.

Questão 4: Quais estratégias estão sendo adotadas para incorporar os $10 \%$ de atividade de extensão ao Currículo?. A Fig.1 apresenta o comparativo das respostas recebidas. 
Fig. 1 - Comparativo das respostas recebidas - Quais estratégias estão sendo adotadas para incorporar os 10\% de atividade de extensão ao Currículo?

\section{Quais estratégias estão sendo adotadas para incorporar os $10 \%$ de atividade de extensão ao Currículo?}

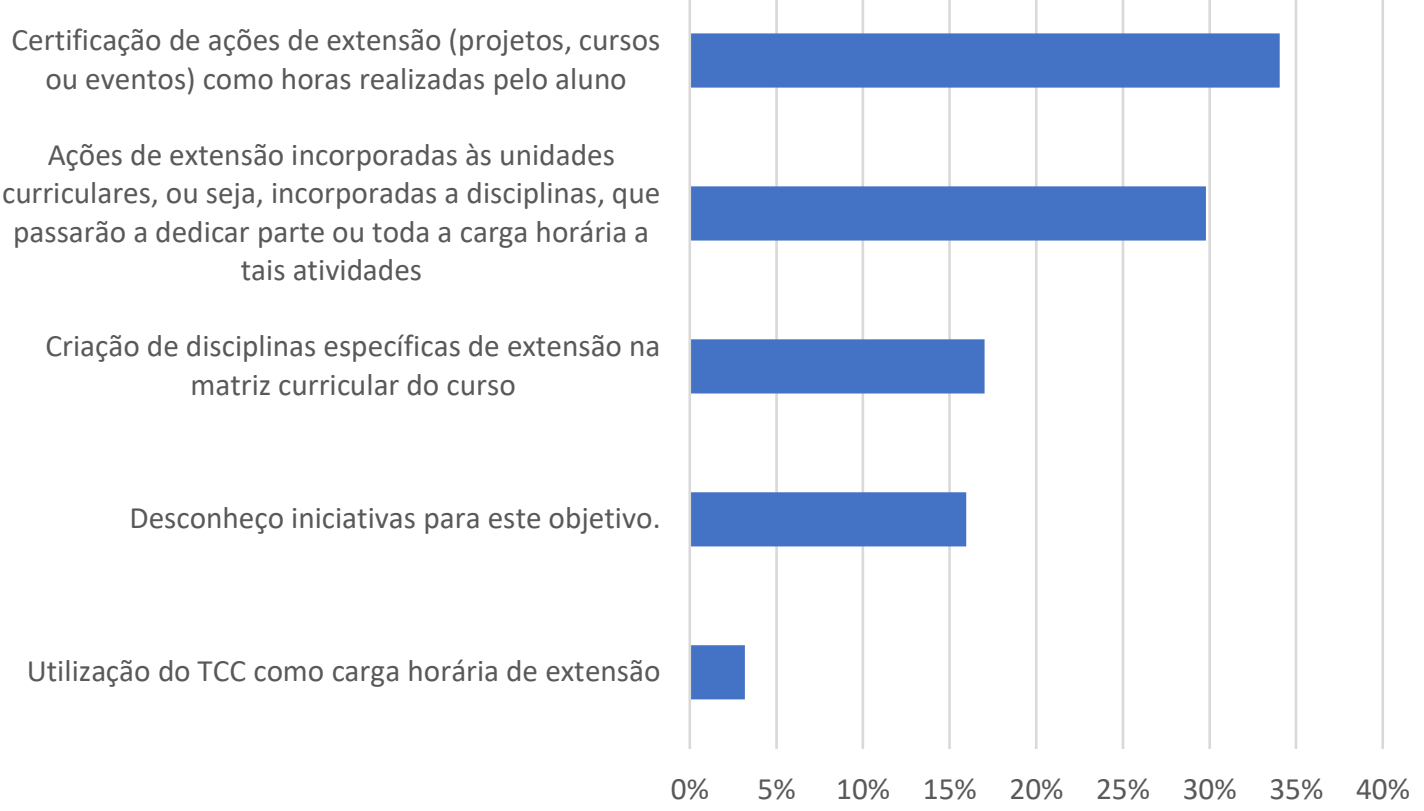

Nota-se que a principal opção é pela certificação de atividades desenvolvidas extraclasse pelos alunos (34\%) e na sequência pela incorporação de atividades de extensão nas disciplinas (30\%). A criação de disciplinas específicas para a extensão foi opção para 17\%. O uso do Trabalho de Conclusão de Curso - TCC como atividade de extensão se mostrou pequeno, apenas 3\%. Enquanto o desconhecimento de atividades ainda é elevado 16\%. Verifica-se assim um desconhecimento ou dificuldades para operacionalização do TCC como extensão o que poderia ser conseguido desde que o projeto trate de um problema aplicado e com devolutiva para a sociedade e assim pudesse computar uma carga significativa de horas para a curricularização da Extensão.

Questão 5: Em sua opinião, qual o perfil docente para conduzir atividades de extensão na IES? - As respostas obtidas foram compiladas no quadro 1 a seguir:

Quadro 1 - Em sua opinião, qual o perfil docente para conduzir atividades de extensão na IES? - compilado

\begin{tabular}{|l|c|c|}
\hline \multicolumn{1}{|c|}{ Termo } & Quantidade & $\%$ \\
\hline Flexível & 1 & 3 \\
\hline Generalista & 1 & 3 \\
\hline Empreendedor & 2 & 6 \\
\hline Criativo & 3 & 9 \\
\hline Dinâmico & 5 & 16 \\
\hline Integrador & 8 & 25 \\
\hline Prático & 12 & 38 \\
\hline
\end{tabular}


Verifica-se pelo levantamento realizado que o perfil do docente é predominantemente de um docente mais voltado à questões práticas (projetos) que saiba integrar conhecimentos e ser um articulador com a sociedade e que tenha um perfil dinâmico, ou seja, busque problemas e soluções que promovam uma interação voltada mais a ação, "mão-na-massa".

As respostas à Questão 6: Sua IES já promoveu alguma capacitação docente voltada à formação de professores para a extensão?, são apresentadas na Fig. 2 a seguir:

Fig. 2 - Sua IES já promoveu alguma capacitação docente voltada à formação de professores para a extensão?,

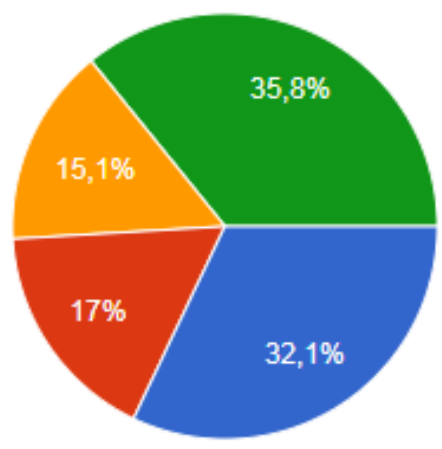

Já promoveu alguma capacitação docente voltada à extensão

Ainda não promoveu alguma capacitação docente voltada à extensão

Pensa em promover alguma capacitação docente voltada à extensão

Desconheço iniciativas para este objetivo.

Observa-se que a capacitação docente voltada à atividades extensionistas ainda carece de atenção pelas IES o que abre caminho para a organização de ações e eventos voltados ao tema.

Questão 7: Que itens deveriam constar de uma capacitação docente voltada à extensão?

\begin{tabular}{|l|c|c|}
\hline \multicolumn{1}{|c|}{ Termo } & Quantidade & $\%$ \\
\hline Técnicas de negociação & 1 & 2 \\
\hline Gestão de projetos & 1 & 2 \\
\hline Como oferecer serviços de projetos de Engenharia & 1 & 2 \\
\hline Como trabalhar com empresas juniores & 1 & 2 \\
\hline Fontes de financiamento da Extensão & & \\
\hline Prestação de contas & 1 & 2 \\
\hline Avaliação da Extensão & 1 & 2 \\
\hline Empreendedorismo & & \\
\hline Conhecimento dos atores locais (sociedade / empresas) & 1 & 2 \\
\hline Metodologias ativas & 1 & 2 \\
\hline Cases de Extensão & 5 & 10 \\
\hline Políticas de Extensão & 5 & 10 \\
\hline
\end{tabular}


Observa-se que a capacitação docente vista pelos próprios docentes, carece principalmente da melhor disseminação dos conceitos e políticas voltadas à Extensão, assim como a divulgação de cases de sucesso para que os docentes possam visualizar como aplicar a Extensão em suas práticas.

Questão 8: É claro para você a diferença entre as ações realizadas no âmbito da curricularização da extensão e as atividades curriculares complementares?

\begin{tabular}{|l|l|}
\hline IES Pública & Sim $-28(68 \%)$ / Não $-9(22 \%)$ \\
\hline IES Privada & Sim $-7(58 \%) /$ Não $-4(33 \%)$ \\
\hline
\end{tabular}

Observa-se ainda uma percepção tênue entre o que são as práticas de extensão previstas na resolução que preconizam o aluno como ator principal e fazedor da atividade e as atividades complementares que geralmente mesclam ações onde o aluno tem papéis ativos e passivos como mero participante de um curso.

Questão 9: Caso queira, apresente aqui algum exemplo de atividade de extensão que vem sendo realizada na sua IES

Dentre as informações enviadas destacam-se:

- Atividades relativas à segurança do trabalho para a sociedade

- Atividades voltadas à disseminação de práticas ambientais sustentáveis.

- Aula de informática para idosos

- Canal do cálculo: um objeto de aprendizagem

- Canteiro Escola

- Coleta contínua de dados de consumo de consumidores de energia elétrica residenciais, comerciais e industriais.

- Competições

- Consultorias para empresas.

- Curso pré-vestibular oferecido pela Universidade

- Cursos voltados à comunidade local ministrados pelos estudantes.

- Empresa Junior de Engenharia

- Ensaio de ruptura de pontes de macarrão em escolas de ensino médio

- Festivais

- Laboratório Aberto

- Projeto e execução de parte elétrica e de redes em escolas públicas

- Projetos de divulgação científica para a comunidade

- Projetos de energia alternativa para comunidades carentes

- Projetos de extensão com alunos de Ensino Médio.

- Projetos de Formação de Engenheiros e Cidadania.

- Projetos de sustentabilidade junto a associações de catadores

- Projetos interdisciplinares para competição (mini-baja, robótica, aeromodelismo, solares, entre outros).

- Projetos voltados para motivar as meninas para áreas STEM

- Semanas de curso 
Dentre as práticas elencadas na pesquisa depreende-se de modo geral as seguintes ações:

- Cursos ou oficinas montadas para comunidades específicas (formação continuada em saúde, educação básica, questões rurais/urbanas etc.)

- Disponibilização de conteúdos de "divulgação científica" em mídias convencionais ou on-line

- Programas de complemento (recuperação) para estudantes da Educação Básica

- Desenvolvimento de soluções tecnológicas para comunidades diversas (desenvolvimento de aplicativos, softwares, guias etc.)

\section{CONSIDERAÇÕES FINAIS}

A curricularização da Extensão é uma prática inovadora que deve ser assimilada pelo corpo discente e docente para que possa ser trabalhada de forma adequada. O planejamento das atividades é fundamental para que efetivamente seja uma ação transformadora da sociedade. Nota-se ainda um maior desenvolvimento e disseminação do conceito de Extensão junto às instituições públicas, carecendo as IES privadas de maior aproximação e desenvolvimento de ações neste quesito. Uma maior disseminação do arcabouço teórico-prático de como aplicar este conceito nos cursos de Engenharia deve ser uma das principais ações a serem conduzidas pelos gestores e pela ABENGE nos próximos anos.

\section{REFERÊNCIAS}

ABMES - ASSOCIAÇÃO BRASILEIRA DE MANTENEDORAS DE ENSINO SUPERIOR - Educação Superior Comentada - A utilização de 10\% da carga horária dos cursos superiores para atividades de extensão Ano $4 \cdot \mathrm{N}^{\mathrm{o}} 21 \bullet 06$ de julho de 2016 - Gustavo Fagundes Disponível em: https://abmes.org.br/colunas/detalhe/1666/educacao-superior-comentada-a-utilizacao-de10-da-carga-horaria-dos-cursos-superiores-para-atividades-de-extensao Acesso em: 06 dez. 2019.

BENETTI, P. C.; SOUSA, A. I.; SOUZA, M. H. N. Creditação da Extensão Universitária nos Cursos de Graduação - Relato De Experiência. Disponível em: http://www.unesp.br/Home/proex/artigo_experiencia-ufrj.pdf Acesso em: 06 dez. 2019.

COIMBRA, A. L. S. et al. Mapeamento da Inserção da Extensão nos Currículos dos Cursos de Graduação das Instituições Públicas de Educação Superior Brasileira Relatório Final FORPROEX

Disponível

em:

https://curricularizacaodaextensao.paginas.ufsc.br/files/2019/06/RELAT\%C3\%93RIO-

FINAL-MAPEAMENTO-INSERCAO-EXTENSAO-FORPROEX.pdf Acesso em: 06 dez. 2019.

COLLADO, D. M.; OLIVEIRA, N. C.; CARNEIRO, P. O. Extensão universitária e flexibilização curricular na UFMG. Disponível em: https://www.ufmg.br/proex/revistainterfaces/index.php/IREXT/article/view/69 Acesso em: 06 dez. 2019. 
IFSC - Instituto Federal de Santa Catarina - Curricularização da Extensão - Disponível em: https://curricularizacaodaextensao.ifsc.edu.br/ Acesso em: 06 dez. 2019.

IMPERATORE, S. L. B.; PEDDE, V. Curricularização" da extensão universitária no Brasil - questões estruturais e conjunturais de uma política pública. Disponível em: http://curricularizacaodaextensao.ifsc.edu.br/files/2016/06/1_Artigo_Curricularizaca_da_Exte nsao_Universitaria_no_Brasil.pdf Acesso em: 06 dez. 2019.

MEC- RESOLUÇÃO No 7, DE 18 DE DEZEMBRO DE 2018 - Estabelece as Diretrizes para a Extensão na Educação Superior Brasileira. Disponível em: http://portal.mec.gov.br/index.php?option=com_docman\&view=download\&alias=104251rces007-18\&category_slug=dezembro-2018-pdf\&Itemid=30192 Acesso em: 06 dez. 2019.

SERVA, F. M., BRANDÃO, C. da Fonseca. Responsabilidade Social da Educação Superior: oportunidades e desafios da curricularização da extensão para instituições do setor privado - Associação Brasileira de Mantenedoras de Ensino Superior (ABMES) - Disponível em: https://responsabilidadesocial.abmes.org.br/noticias/artigos/360-responsabilidade-socialda-educacao-superior-oportunidades-e-desafios-da-curricularizacao-da-extensao-parainstituicoes-do-setor-privado Acesso em: 06 dez. 2019.

UERN - Universidade do Estado do Rio Grande do Norte - Curricularização da Extensão - Disponível em: http://proex.uern.br/default.asp?item=proex-documentos-legisla\%E7\%E3o Acesso em: 06 dez. 2019.

UFAL - Universidade Federal de Alagoas - Curricularização da Extensão - Disponível em: https://ufal.br/ufal/extensao/documentos/rco-n-04-de-19-02-2018.pdf/view Acesso em: 06 dez. 2019.

UFC- Universidade Federal do Ceará - Curricularização da Extensão - Disponível em: http://www.prograd.ufc.br/wp-content/uploads/2018/03/curricularizacao-da-extensaoresolucao-n-28-cepe-2017.pdf Acesso em: 06 dez. 2019.

UFMG - Universidade Federal de Minas Gerais - Curricularização da Extensão Disponível e em: https://www2.ufmg.br/proex/content/download/8087/52064/file/Resolucao\%20CEPE\%20Formacao \%20em\%20Extensao.pdf Acesso em: 06 dez. 2019.

UFPEL - Universidade Federal de Pelotas - Curricularização da Extensão - Disponível em: $\quad$ https://wp.ufpel.edu.br/scs/files/2016/03/Resolu\%C3\%A7\%C3\%A3o-COCEPE-062016.pdf Acesso em: 06 dez. 2019.

UFRJ - Universidade Federal do Rio de Janeiro - Curricularização da Extensão Disponível em: https://extensão.ufrj.br/index.php/creditacao/regulamentacao Acesso em: 06 dez. 2019.

UFSC - Universidade Federal de Santa Catarina - Curricularização da Extensão Disponível em: https://curricularizacaodaextensao.ufsc.br/ Acesso em: 06 dez. 2019. 
UNB - Universidade de Brasília - Curricularização da Extensão - Disponível em: http://www.dex.unb.br/apresentacaodacurricularizacao Acesso em: 06 dez. 2019.

UNIFESP - Universidade Federal de São Paulo - Curricularização da Extensão Disponível em: https://www.unifesp.br/reitoria/proex/curricularizacao/documentos Acesso em: 06 dez. 2019.

UPE - Universidade de Pernambuco Curricularização da Extensão - Disponível em: http://www.upe.br/anexos/extensao/documentos/Guia_da_Creditacao_da_Extensao.pdf Acesso em: 06 dez. 2019.

\title{
THE CURRICULARIZATION OF EXTENSION AND ITS APPLICATION IN ENGINEERING SCHOOLS
}

\begin{abstract}
The extension curriculum, or extension (curricular) accreditation, a strategy provided for in the National Education Plan (PNE), was regulated by Resolution No. 7 MEC / CNE / CES, of December 18, 2018. This resolution brings as great issue to be implemented in Higher Education Institutions, compliance with the 10\% minimum workload dedicated to extension. But the big question remains: how to develop a curriculum that contemplates this percentage of workload without compromising the contents that must be developed in the course? What is the teacher's profile? How are the Engineering Schools adapting? This article presents a survey carried out with the Engineering Schools associated with ABENGE and then presents an overview of the proposals in progress.
\end{abstract}

Key-words: DCN, Curriculum, Extension. 